\title{
COMPORTAMENTUL DE REPRODUCERE AL RANIDELOR VERZI: ANALIZĂ SINTETICĂ
}

\author{
Cozari Tudor ${ }^{1,2}$, Gherasim Elena ${ }^{1}$ \\ 1'nstitutul de Zoologie al Ministerului Educației, Culturii și Cercetării, Chiși- \\ nău, R. Moldova \\ 2Universitatea de Stat din Tiraspol, Chișinău, R. Moldova \\ cozaritudor@gmail.com,gherasimlenuta@gmail.com
}

https://doi.org/10.53937/9789975315975.06

\begin{abstract}
Amphibians, represents a special study object for researchers because this are the first vertebrate animals that have conquered the dry land. Internationally, this study being analyzed from the most diverse points of view: morphological, physiological, systematic, phylogenetic, ecological, and so on, but nationally the research is incomplete.

For this purpose, the authors carried out a complex study and deciphered the most complicated aspects of reproductive behavior of these vertebrate animals. The reproduction behavior of green frogs is one that evolved during their evolution and is one of the important components of the process of adaptation of amphibian populations to the conditions of the temperate environment of the Earth.
\end{abstract}

Key words: amphibia green frogs, reproduction, Moldova

\section{INTRODUCERE}

Pentru elucidarea problemelor ce țin de comportamentul de reproducere al amfibienilor din complexul ranidelor verzi (Rana ridibunda, $R$. lessonae, $R$. esculenta) în ecosistemele țării noastre, este necesar de a realiza o analiză sintetică detaliată referitoare la subiectul abordat, care, în continuare, va servi drept suport științifico-metodologic întru soluționarea subiectelor abordate în batracologie.

Datele științifice existente până la ora actuală cu privire la reproducerea ranidelor verzi demonstrează un comportament nupțial specific al amfibienilor complexului ranidelor verzi, exprimat prin teritorialismul masculilor, aceștia formând grupuri de reproducere de tip "arenă" (de tip "lek" - din terminologia engleză), amplasate în locuri neadânci, bine 
insolate și cu vegetație acvatică bogată, care este folosită pentru staționarea masculilor [2, 8]. În cadrul arenelor se desfășoară procesul selectării partenerilor conjugali și formarea cuplurilor, care este realizată în baza atragerii femelelor de către masculi prin cântece nupțiale caracteristice, dar și în urma interacțiunilor antagoniste dintre masculi și a substituirii din cupluri a masculilor mai slabi de către masculii mai puternici. În urma unor investigații de durată a unei populații mixte din Europa de Vest, alcătuite din toate cele trei specii de ranide verzi, s-a constatat că formarea cuplurilor nu este un proces întâmplător, cel mai frecvent cuplurile se formau din indivizi conspecifici ai speciei $R$. lessonae sau din masculi de $R$. esculenta și cele mai mari femele ale speciei $R$. lessonae, pe când cuplurile formate din masculi și femele de $R$. esculenta erau foarte rare. În baza acestor observații a fost înaintată ipoteza conform căreia se consideră că fenomenul izolării reproductive din cadrul complexului ranidelor verzi se datorează, probabil, existenței unor deosebiri interspecifice evidente în dimensiunile corpului reproducătorilor $[5,6]$.

\section{MATERIAL ȘI METODE}

Aria de studiu include habitate acvatice ale ranidelor verzi din cadrul ecosistemelor naturale și antropizate din zonele umede ale Codrilor Centrali. Observațiile, colectarea și obținerea datelor științifice despre comportamentul de reproducere a specimenelor complexului ranidelor verzi s-au efectuat în zona de Centru a Republicii Moldova: Rezervația "Codrii" și sectoarele limitrofe din sud-vestul ei și Grădina Botanică (Institut) a MECC.

Speciile compexului ranidelor verzi (Rana ridibunda, Rana lessonae, Rana kl. esculenta) au fost cercetate pe parcursul anilor 2013 - 2018, în decursul perioadei active a ciclului anual de viață (martie - noiembrie). În biotopurile acvatice au fost cercetate toate cele 3 specii de ranide verzi, inclusiv categoriile lor de sex.

Determinarea speciilor complexului ranidelor verzi a fost efectuată prin metode clasice deductive, care includ utilizarea anumitor parametri și/sau indici morfologici, precum și unele caracteristici ale coloritului corpului: culoarea de fond a spatelui, numărul de dungi de pe mem- 
bre. Forma, dimensiunile, amplasarea petelor de pe partea inferioară a corpului etc., s-au analizat conform metodelor clasice de cercetare, prin descrierea detaliată a culorii generale, stabilirea prezenței anumitor pete cromatice, forma, repartiția, dimensiunile acestora etc.[3, 4, 7].

Comportamentul reproductiv al speciilor de ecaudate din grupul ranidelor verzi a fost studiat prin metoda observaţiilor directe de durată în condiţii de teren. Cercetările în cauză având scopul elucidării comportamentului partenerilor conjugali pe parcursul reproducerii și anume:

a) procesul deplasării reproducătorilor din locurile de iernare spre locurile de reproducere; b) repartizarea spaţială a reproducătorilor în bazinele acvatice;

c) procesul selectării teritoriilor individuale, atragerea partenerului sexual și formarea cuplurilor conjugale etc.

Fiecare din „demonstraţiile" comportamentale ale masculilor și femelelor erau înregistrate sub forma unei secvenţe de imagini (10 - 15), apoi studiate și analizate la computer. Prelucrarea și analiza datelor etologice colectate ne-a permis de a elabora un model integral al comportamentului nupţial al ranidelor verzi.

\section{REZULTATE ȘI DISCUȚII}

Speciile de ranide verzi fac parte din categoria amfibienilor cu reproducere lungă și, totodată, târzie. În baza investigațiilor realizate în habitatele naturale din Codrii Centrali pe întreaga durată a perioadei de reproducere, am elaborat un model integral al comportamentului reproductiv al ranidelor verzi; care reprezintă, din punct de vedre spațial și temporal, întreaga complexitate de faze reproductive ce se manifestă la nivel biologic, ecologic și comportamental.

Reieșind din specificul strategiei de reproducere a ranidelor verzi, primii spre stațiile de reproducere care se află în cadrul aceluiași bazin acvatic, se deplasează masculii. Deplasările masculilor se realizează în mod solitar; de regulă, în jumătatea a doua a zilei și seara. Astfel, la a 7-12-a zi de la ieșirea din hibernare, masculii încep deja să se deplaseze spre stațiile de reproducere. Ei se stabilesc în sectoarele mai puțin adânci (15$80 \mathrm{~cm}$ ), crescute cu vegetaţie submersă și bine insolate; densitatea lor 
crescând de la o zi la alta, pe măsură ce temperatura mediului sporește. Strategia de reproducere a ranidele verzi se bazează pe:

a) teritorialismul masculilor;

b) atracția femelelor prin vocalizare (și/sau căutarea activă a femelelor de către masculi).

Comportamentul teritorial al masculilor. Masculii ranidelor verzi manifestă un comportament teritorial evident. Aceștia, o dată ajunși pe sectoarele prielnice ale bazinelor acvatice de reproducere, ocupă teritorii individuale pe oglinda apei și se asociază în așa-numitele grupuri de reproducere de "tip arenă". Arenele nupțiale sunt amplasate în apropiere de malurile mai puțin înalte, la adâncimi nu prea mari, fiind bine insolate, bogate cu vegetație acvatică lângă și/s-au în cadrul arenelor nupțiale. În cadrul arenelor se desfășoară procesul de selectare a partenerilor conjugali și de formare a cuplurilor, care se realizează în baza comportamentului teritorial al masculilor și a atragerii femelelor de către masculi prin emiterea cântecelor de reclamare. Suprafața arenelor nupțiale variază în funcție de suprafața habitaelor acvatice și a spațiilor favorabile reproducerii amfibienilor; aceasta variind de la 14-16 m² (cu un număr de 18-20 de masculi) pînă la 55-85 m² (și, respectiv, 85-115 masculi).

În cadrul arenelor nupțiale, masculii ocupă un teritoriu individual (de 1,2-1,6 $\mathrm{m}^{2}$ ). Acest teritoriu este protejat de către masculi de incursiunile altor intruși. Masculii teritoriali din raza de 3-4 $\mathrm{m}$ a arenei nupțiale formează un grup reproductiv personalizat (constituit din 4-6 masculi), în cadrul căruia fiecare mascul teritorial (mascul-rezident) se află în anumite relații de rivalitate pentru teritoriu și femele; soluționarea lor, de regulă, se realizează pe cale sonoră sau prin interacțiuni fizice directe.

Vocalizarea masculilor. În teritoriile individuale din cadrul arenelor nupțiale masculii teritoriali manifestă o activitate periodică de vocalizare, care se desfășoară, la început, în orele serii (parțial, și noaptea), iar mai apoi și în timpul zilei (în faza de vârf a perioadei nupţiale).

Vocalizarea masculilor are două funcții vitale importante:

a) de protecție a teritoriului (numit și cîntec teritorial, fiind emis de către masculul-teritorial la apariția în spațiul protejat a altui mascul);

b) de atracție a femelelor (femelele își selectează partenerii în baza 
frecvenței și intensității semnalelor sonore; fenomen stabilit anterior și la alte specii autohtone de amfibieni (Cozari, 2010).

Teritoriul individual la ranidele verzi, ca și la alte specii de ecaudate, este protejat de incursiunile altor masculi-intruși prin semnale sonore de agresie sau prin interacţiuni competitive directe [2].

Semnalele sonore de agresie sunt emise de către masculii-teritoriali în cazurile când intrușii intră în teritoriul protejat sau, chiar, îi atacă pe masculii-teritoriali. Astfel, între masculii vecini din cadrul arenei nupțiale se desfășurau interacțiuni antagoniste frecvente, caracterizate prin ciocniri directe pe parcursul cărora fiecare dintre ei încerca să-și alunge adversarul din teritoriul individual. După aceste interacțiuni directe destul de violente, masculii se îndepărtau unul față de celălalt la distanțe de circa 30-50 cm, orientându-se în poziție „spate la spate" unul față de altul.

Masculii-teritoriali vecini întreprind incursiuni pe teritoriile celorlalţi masculi-teritoriali în scopul ocupării unui teritoriu străin mai bun; în aceste cazuri atestându-se interacţiuni antagoniste dintre intruși și stăpânii teritoriilor, iar acestea se petrec după următoarele scenarii:

1. Interacţiuni antagoniste reciproce care finalizează cu retragerea masculului-intrus de pe teritoriul masculului-teritorial. La început, ambii masculi se atacă reciproc și fiecare din ei se află atât în poziție de învingător (stă pe spatele adversarului) cât și în poziție de învins (situat de desubtul adversarului), astfel interacțiunea se finalizează cu câștigul masculului-teritorial. Uneori, masculul-intrus îl atacă pe masculul-teritorial; însă când intrusul aude semnalele sonore de agresie, el părăsește teritoriul străin. În al 3-lea tip de interacțiuni antagoniste, la apariţia intrusului, masculul-teritorial îl atacă imediat, emiţând, și semnale acustice de agresie; intrusul în asemenea situații părăsește teritoriul fără a opune careva rezistenţă.

2. Interacţiuni antagoniste care finalizează cu învingerea masculului-teritorial și acapararea teritoriului acestuia de către masculul-intrus.

Drept rezultat, în cazul când masculul-teritorial este de dimensiuni mai mari sau are un comportament mai agresiv, intrusul cedează și se retrage. Și, dimpotrivă, când masculul-intrus are dimensiuni majore sau comportament mai agresiv, acesta iese învingător. 
În rezultatul ciocnirilor directe între masculii fiecărei arenei nupțiale se stabileau anumite relații ierarhice, așa încât masculii-dominanți beneficiau de șansa de a se acupla primii cu femelele care erau atrase de corul puternic al tuturor masculilor din cadrul acelei sau altei arene nupțiale ale lacurilor de reproducere.

Vocalizarea și atragerea femelelor de către masculi. Pe lângă tactica masculilor bazată pe ocuparea și protejarea teritoriilor individuale, o altă tactică eficientă de reproducere constă în vocalizarea masculilor și atragerea femelelor prin cântece de reclamare. Vocalizarea masculilor în cadrul întregii arene nupțiale decurge periodic și se menține până la 5-7 minute: trilurile puternice și ritmice inițiate de unul dintre masculi provocau includerea treptată și rapidă a celorlalți membri ai arenei nupțiale după care, la un moment dat, corul se întrerupea brusc. Alternarea fazelor de vocalizare cu cele de liniște (după principiul "activitate-repaos"), reprezintă un fenomen important al comportamentului nupțial de vocalizare a masculilor deoarece are drept scop, pe de o parte, de a personaliza arena nupțială și de a asigura realizarea procesului de stabilire a relațiilor de dominanță dintre membrii arenelor nupțiale; iar pe de altă parte, el permite economisirea energiei masculilor pe durata vocalizării și le oferă posibilitatea de a menține funcționalitatea sonoră a corurilor pe întreaga perioadă de reproducere.

În timpul emiterii semnalelor sonore de atracție a femelelor, masculii i-au o poziție caracteristică pe oglinda apei, lansând triluri continui cu durata de 10-35 sec; periodic masculii schimbându-și poziția în cadrul teritoriului pentru a cuprinde un spațiu de sonorizare cât mai amplu. Reieșind din acest specific al vocalizării speciei, se poate conchide că sunetele de reclamare ale masculilor (ca și funcţionarea corurilor în general), la etapa inițială, au drept scop nu atât atragerea femelei prin vocalizarea masculilor, cât atragerea femelelor gata de reproducere în stațiile de reproducere. După aceasta, o dată atrase în stațiile acvatice, femelele sunt atrase de către masculii-teritoriali în funcție de parametrii acustici ai sunetelor de reclamare.

Vocalizarea masculilor în zilele calde începe chiar din orele dimineţii (9-10) și, în perioada de vârf a reproducerii, pot continuă până în amurg. 
Atunci când pe parcursul zilei timpul se schimbă brusc (devine posomorât, bate vântul, scade temperatura aerului), corurile încetează. Semnalele de reclamare ale masculilor prezintă o serie de impulsuri ritmice (11-31) ce sunt emise timp de 2-5 secunde; repetate peste fiecare 7-15 secunde. Cântecele de reclamare ale masculilor nu sunt emise în continuu ci periodic, iar durata lor poate să fie de 1,5-4,0 minute.

Conform observațiilor directe de lungă durată realizate în condiții naturale s-a stabilit că cuplurile conjugale se formează nu numai din indivizi ai aceleiași specii, dar și din masculi ai speciei $R$. lessonae și femele ale speciei $R$. ridibunda. În rezultatul încrucișării dintre aceste două specii diferite rezultă hibridul lor - $R$. esculenta. După încheierea procesului de reproducere dintre reproducătorii speciilor $R$. ridibunda și $R$. lessonae la sfârșitul lunii aprilie-începutul lunii mai, oglinda apei a fost ocupată de către specia $R$. esculenta. Strategiile de reproducere ale acestei specii întrunesc aceleași acte reproductive ca și la speciile $R$. ridibunda și $R$. lessonae: teritorialismul masculilor, atracția femelelor prin semnale sonore emise de către masculi etc.

În baza rezultatelor evidențiate cu referire la strategiile de reproducere și inițiere a acestora, se elucidează coexistența în unul și același biotop a două specii atât de apropiate ( $R$. ridibunda, $R$. esculenta).

Comportamentul de reproducere al femelelor. Femelele ranidelor verzi se îndreaptă spre arenele nupțiale mai târziu ca masculii - la a 4-6-a zi de la apariția primilor masculi în stațiile de reproducere. De regulă, femelele se îndreaptă spre acele stații de reproducere unde corurile masculilor sunt mai puternice; aici ele vor beneficia de cele mai favorabile condiții de selectare a partenerilor conjugali și de ovopozitare. Femelele, o dată ajunse în staţiile de reproducere, sunt gata deja de ovopozitare deoarece ovulele acestora sunt deja în faza finală de dezvoltare. Anume aceste femele, intrând în spațiul stațiilor de reproducere, pornesc în căutarea masculilor. În cazul când masculul-teritorial emite semnalele sonore care corespund exigențelor fonetice ale femelei, atunci femela î-l acceptă și îi permite să se acupleze cu ea; de regulă cuplul format în asemenea condiții constă din parteneri asemănători ca dimensiuni corporale. În cazurile când masculul este mai mic și amplexul axial format 
nu este sigur, atunci femela, se eschivează de un asemenea amplex impunând masculul s-o părăsească. În alte cazuri, cu mult mai frecvente, acești masculi de talie mai mică care au interceptat femelele ne potrivite ca dimensiuni, sunt atacaţi și eliminaţi din cuplurile proaspăt formate de către masculii de talie mai mare. După cum au demonstrat un șir de cercetări anterioare referitoare la acuplarea dintre partenerii conjugali asemănători ca dimensiuni [1], acuplarea asortativă la ranidele verzi este eficientă și pe deplin justificată din punct de vedere evolutiv deoarece îi va permite femelei să-și fecundeze întreaga pontă.

Cuplurile formate, rămân în aceleași stații de reproducere unde realizează procesul ovopozitării. Ponta este depusă în decurs de 3-5 ore, și se realizează, de regulă, în orele după-amiezii și seara; ouăle depuse în porții pe fundul bazinelor acvatice sau sunt fixate de vegetația submersă la o adâncime de $25-30 \mathrm{~cm}$.

\section{CONCLUZII}

1. Din arsenalul de strategii de reproducere caracteristice amfibienilor ecaudați, ranidele verzi pe parcursul evoluției au ajuns la manifestarea unui comportament bazat pe folosirea așa numitelor ",arene nupțiale, în cadrul cărora masculii adulți se asociază pentru a disputa primatul în formarea cuplurilor conjugale și, ulterior, a realizării procesului de fecundare și ovopozitare.

2. În cadrul acestor arene nupțiale masculii se folosesc de tactica de atragere a femelelor prin vocalizare; semnalele sonore fiind un indiciu veridic în stabilirea vârstei masculilor și a capacității lor vitale de reproducere. Interacțiunile fizice dintre mascul pentru disputarea teritoriului individual sau a dreptului de intra în posesia femelei reprezintă o a doua modalitate de a învinge în competițiile cu alți masculi pentru a participa la reproducere.

3. Comportamentul de reproducere a ranidelor verzi este unul destul de evoluat în seria stratagemelor elaborate pe parcursul evoluției de către amfibienii ecaudați și reprezintă unul din componentele importante a procesului de adaptare a populațiilor de amfibieni la condițiile mediului înconjurător din zona temperată a Terrei. 
Studiul a fost efectuat în cadrul proiectelor fundamentale 15.187.0211F și 15.817.02.12F realizate la Institutul de Zoologie.

\section{BIBLIOGRAFIE}

1. Cozari T. Etologie ecologică. Chișinău: Litera, 2001.176 p.

2. Cozari T. Strategii de reproducere a amfibienilor. Particularităţile evolutive ecologice în ecosistemele naturale și antropizate. Chișinău: Știinţa, 2010, 288 p.

3. Банников А.Г., Ааревский И. С., Рустамов А. К. Земноводные и пресмыкающиеся СССР. М.: Просвещение, 1971. 304 с.

4. Банников А. Г. и ир. Определитель земноводных и пресмыкающихся фауны СССР. М., 1977. 414 с.

5. Кузьмин С.^. Земноводные бывшего СССР. М.: Т-во науч. иза. KMK, 1999. 298 c.

6. Кузмин, С.^. Земноводные бывшего СССР. Издание второе, переработанное. Москва, 2012. 327 с.

7. Arnold E. N., Burton J. A. Guida dei Rettilii e degli Anfibi d'Europa. Atlante illustrato a colori. In: Franco Muzzio and editori, 1986, 244 p.

8. Bee M.A., Perrill S.A., Owen P.C. Male green frogs lower the pitch of acoustic signalsin defense of territories: a possible dishonest signal of size? In: Behav. Ecol. 2000. Vol. 11, p. 168-177. 